\title{
Deterrence and the Celerity of the Death Penalty - A Neglected Question in Deterrence Research
}

William C. Bailey

Cleveland State University, w.bailey@csuohio.edu

Follow this and additional works at: https://engagedscholarship.csuohio.edu/clsoc_crim_facpub

Part of the Criminology Commons

How does access to this work benefit you? Let us know!

Publisher's Statement

(c) 1980 Oxford University Press

\section{Original Citation}

Bailey, W. C. (1980). Deterrence and the Celerity of the Death Penalty: A Neglected Question in Deterrence Research. Social Forces, 58(4), 1308-1333.

\section{Repository Citation}

Bailey, William C., "Deterrence and the Celerity of the Death Penalty - A Neglected Question in Deterrence Research" (1980). Sociology \& Criminology Faculty Publications. 73.

https://engagedscholarship.csuohio.edu/clsoc_crim_facpub/73

This Article is brought to you for free and open access by the Sociology \& Criminology Department at EngagedScholarship@CSU. It has been accepted for inclusion in Sociology \& Criminology Faculty Publications by an authorized administrator of EngagedScholarship@CSU. For more information, please contact library.es@csuohio.edu. 


\title{
DETERRENCE AND THE CELERITY OF THE DEATH PENALTY: A NEGLECTED QUESTION IN DETERRENCE RESEARCH
}

\author{
William C. Bailey, Cleveland State University
}

This article was originally published in:

Bailey, William C. (1980). Deterrence and the Celerity of the Death Penalty: A Neglected Question in Deterrence Research. Social Forces, 58(4),1308-1333.

Post-print standardized by MSL Academic Endeavors, the imprint of the Michael Schwartz Library at Cleveland State University, 2013

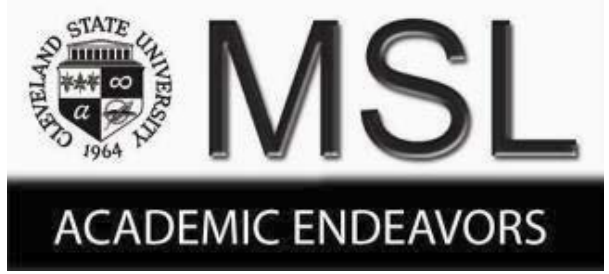




\title{
Deterrence and the Celerity of the Death Penalty: A Neglected Question in Deterrence Research*
}

\author{
W I L L I A M C. B A I L E Y, Cleveland State University
}

\section{ABSTRACT}

This paper examines the deterrent effect of the celerity of the death penalty on homicide rates. Although in recent years there have been a number of investigations of the certainty of execution and deterrence, the effect of celerity of execution has not been examined empirically. As a result, we can only speculate about the merit of the deterrence hypothesis for the celerity of executions, and how previous deterrence and death penalty investigations may be biased due to celerity being ignored.

The deterrent effect of the certainty and celerity of the death penalty on homicide rates is examined cross-sectionally for states. Multiple measures of execution and homicide rates are considered, along with various sociodemographic variables in investigating the possible spuriousness of the findings. Analysis consistently fails to provide support for the deterrence argument for the certainty and celerity of executions. Rather, the results fall well within the pattern of negative findings of over five decades of deterrence and death penalty research in the United States.

In response to the growing recognition of the limitations of the early studies of the deterrent effect of the death penalty (Bye; Kirkpatrick; Schuessler; Sellin a, b; Sutherland; Vold) a number of investigations of this important question have been published in the last few years (Bailey, a, b, c, d; Black and Orsagh; Bowers and Pierce; Ehrlich; Forst; Passell; Passell and Taylor; Yunker). Although the recent studies have addressed some important questions, and have played a part in a number of recent death penalty cases brought before the United States Supreme Court, they have not settled the deterrence controversy. ${ }^{1}$ Rather, these recent investigations have

\footnotetext{
*The research reported here was in part supported by funds granted to the Institute for Research on Poverty at the University of Wisconsin-Madison by the Department of Health, Education, and Welfare pursuant to the provisions of the Economic Opportunity Act of 1964. The conclusions expressed here are those of the author. An earlier version of this article, under the same title, appeared as a discussion paper (\#532-78) at the Institute for Research on Poverty, University of Wisconsin-Madison. Copies are available by writing the author or the Institute.
} 
brought some writers to opposite conclusions, and have raised additional questions about deterrence and the death penalty (Gibbs, a, b). One of these questions, and the issue examined here, is the extent to which the results of these recent studies might be biased due to neglect of the deterrent effect of the celerity of executions.

Dating back to the writings of Beccaria and Bentham, proponents of deterrence have argued that in order for legal sanctions to be effective deterrents to crime, they must be (1) severe, (2) administered with certainty, (3) administered swiftly (celerity), and (4) administered publicly. The presumed importance of the celerity of punishment is illustrated by Beccaria:

An immediate punishment is more useful; because the smaller the interval of time between the punishment and the crime, the stronger and more lasting will be the association of the two ideas of "crime" and punishment; so that they may be considered, one as the cause, and the other as the unavoidable and necessary effect. . . Delaying the punishment serves only to separate these two ideas, and thus affects the minds of the spectators rather as being a terrible sight than the necessary consequences of a crime, the horror of which should contribute to heighten the idea of punishment. (75-6; emphasis added).

Similarly, in a more recent discussion, Jeffery also emphasizes the importance of the celerity and certainty of sanctions as deterrents. For example, in accounting for the negative evidence for the death penalty he argues:

The uncertainty of capital punishment is one major factor in the system. Another factor is the time element. A consequence [the death penalty] must be applied immediately if it is to be effective. . . . The lesson to be learned from capital punishment is not that punishment does not deter, but that the improper and sloppy use of punishment does not deter or rehabilitate (299).

Because death penalty investigators have failed to consider the celerity of executions, we can only speculate about the deterrent effectiveness of this dimension of punishment. In addition, if celerity is an important deterrent to murder, then ignoring this factor may have biased the findings in previous investigations of the severity (imprisonment versus execution) and certainty (execution rates) of the death penalty. As Black and Orsagh point out, by their (and others') failure to include the celerity of punishment in their deterrence model, results for the sanction variables that were considered may be biased against confirming the neoclassical hypothesis; parameter estimates for the sanction variables will be biased if some important variable(s) is excluded from the model. ${ }^{2}$

I, too, can only speculate about the deterrent effect of the celerity of executions on murder, and how ignoring this factor may have led to biased results in previous investigations. Proponents of deterrence may be correct about celerity, for as Geerken and Gove argue, "the greater the speed with which punishment occurs (the brevity of the reaction time), the greater the 
effectiveness of the deterrence system" (500). On the other hand, the celerity of the death penalty may have little-to-no deterrent value for murder:

Surely it is difficult to see how, in the case of general deterrence, a short time interval between an offense and the punishment of an alleged offender increases the deterrent impact on others. Thus on reading that someone has been executed for first-degree rape, why would the reader be deterred more (assuming any impact at all) if the alleged rape took place a year ago rather than two years ago? (Gibbs, b, 289).

In addition, Gibbs further argues, "why would he or she [the would-be offender] be deterred more if the crime took place six weeks rather than one year previously?" (a, 9). Although skeptical, Gibbs does concede, however, that the celerity hypothesis does warrant investigation. ${ }^{3}$

The present research is a partial replication and extension of a number of investigations. Consistent with most studies, I examine the deterrence hypothesis of a significant inverse relationship between states' homicide rates and (1) the certainty of execution for homicide, (2) the certainty of imprisonment for homicide, and (3) the severity of imprisonment for homicide. In addition, I also examine the deterrence hypothesis of (4) a significant positive relationship between the celerity of the death penalty-the elapsed time between the sentencing and execution of convicted murderers-and homicide rates; the greater the elapsed time between sentencing and execution of convicted murderers, the higher the homicide rate.

Analysis is solely confined to death penalty states because it makes no theoretical sense to talk about celerity of executions in abolitionist jurisdictions. Further, by limiting the analysis to these states, it will be possible to examine the relative deterrent effect of both imprisonment and the death penalty. In addition, by incorporating the celerity of executions, it will be possible to examine how the exclusion of this variable might have biased previous studies.

As in previous investigations, sociodemographic factors are considered to control for the possible spuriousness of the sanction-offense rate relationship. For reasons discussed later, analysis is confined to a cross-state examination of the deterrence question for 1960.

\section{Review of the Literature}

Beginning in the mid-1970s a handful of multivariate analyses of deterrence and the death penalty began to appear in criminology, economics, and law journals. In Ehrlich's research, widely publicized, the relationship between certainty of execution and homicide rates was examined longitudinally for the period 1933 to 1969; simultaneously, sociodemographic and law enforcement factors were considered as control variables. Using na- 
tionally aggregated data for these years, Ehrlich's analysis led him to conclude that "an additional execution per year over the period in question may have resulted, on average, in seven to eight fewer murders" (414).

Ehrlich's findings have been challenged on a number of grounds. First, he failed to differentiate between retentionist and abolitionist jurisdictions in estimating annual probabilities of execution, which of course, is misleading since the probability of execution in abolitionist states is zero. Second, the validity of his findings rests on the assumption that the form of the relationship between executions and homicides is the same from 1933 to 1969 . Examinations of this question for varying periods between 1933 and 1969 led both Bowers and Pierce and Passell and Taylor to reject the assumption of temporal homogeneity. Third, for each year 1933 to 1969, Ehrlich aggregated his execution, homicide, and control variables on a national level. Such a procedure obviously does not take into consideration the substantial state to state variation in (1) levels of homicide (in both types of states), (2) execution practices (in retentionist jurisdictions), and (3) the sociodemographic factors used as control variables. Because of these and other difficulties, Passell and Taylor conclude that Ehrlich's research has to be viewed with extreme skepticism, and "it is prudent neither to accept nor reject the hypothesis that capital punishment deters murder" (12).

In another recent investigation, Yunker examined the executionoffense rate relationship by (1) using an alternative measure of certainty of execution-the actual number of executions per year for periods from 1933 to 1972 , (2) considering only unemployment as a control variable, and (3) considering a zero and three-year time lag between executions and homicides. His research provides support for the deterrence hypothesis. For the period 1960 to 1972 (the execution-homicide rate relationship is positive, or low-negative, for more extended periods), he reports a significant inverse relationship between executions and homicide rates for the threeyear lag model, and concludes that "one execution will deter 156 murders" (65). Nonlagged execution rates and homicide rates were not significantly related.

Yunker's research suffers from the same objections raised about Ehrlich's study: (1) he aggregated his data on a national level; and (2) he failed to differentiate between abolitionist and retentionist jurisdictions. In addition, he chooses to ignore his less conclusive findings for the period 1933 to 1959.

In a third investigation, Forst examined changes in execution and homicide rates from 1960 to 1970 cross-sectionally for states, with sociodemographic and imprisonment data being considered as control variables. Exploring a number of execution-homicide models, he consistently reports a nonsignificant relationship between executions and homicides. He did find, however, changes in the certainty of imprisonment for homicide from 
1960 (41.3 percent) to 1970 ( 34.6 percent) to be significantly related to changes in homicide rates ( +53 percent) between these years. Forst concludes that this factor, along with the increased affluence during the 1960s, is the major contributor to the increase in homicide during the decade.

In two final studies of note, Bailey (d) and Black and Orsagh examined the relationship between the certainty of execution and homicide rates for 1950 and 1960 cross-sectionally for states. For neither year does either of these studies provide support for the deterrence argument. Both Bailey and Black and Orsagh find execution and homicide rates to be positively related. In contrast, findings for the severity and certainty of imprisonment are much less consistent in each investigation, with the coefficients varying in sign, size, and level of significance for different years, and sanction-offense rate models. Bailey and Black and Orsagh agree, however, that they find no evidence consistent with the deterrence argument for the death penalty.

The above research fails to provide an altogether consistent pattern of findings. With the exception of the Ehrlich and Yunker studies, analyses have failed to detect a substantial inverse relationship between execution and homicides rates. Typically, these two variables have been found to be either positively, or only slightly negatively associated. In addition, because of the difficulties with the Ehrlich and Yunker studies, their contrary findings have to be viewed with extreme caution. However, and as Bailey and Orsagh point out, until the celerity of the death penalty is considered as a deterrent to murder, the negative findings resulting from recent investigations will also have to be viewed with caution.

\section{Methods and Procedures}

The deterrence effect of the certainty and celerity of execution, and the certainty and severity of imprisonment on state homicide rates is examined to provide a more comprehensive analysis of the deterrence question. Multiple measures of the certainty of execution and homicide rates are investigated and a variety of sociodemographic factors are considered as control variables.

\section{HOMICIDE RATES}

In the absence of theoretically appropriate figures for first-degree murder, F.B.I. figures for murder and nonnegligent manslaughter are used as an indicator of capital homicide rates. Because this homicide category includes all felonious homicides, and is thus more inclusive than first-degree murder, it must be assumed that the ratio of capital to total criminal homicides 
is constant from state to state, so that F.B.I. figures provide a reasonably good indicator of capital offenses. ${ }^{4}$

Despite the widespread use of F.B.I. figures in death penalty investigations, the bias resulting from this practice remains unknown, for no one has succeeded in accurately counting the capital offenses hidden in these data (Bedau; Gibbs, a, b; Sellin, a). The bias may not be substantial, however, for Bailey $(a, b, c)$ reports similar findings for certainty of execution when F.B.I. figures and prison admission figures for first-degree murder are used as indicators of capital homicide rates. ${ }^{5}$ In addition, it can be argued that the death penalty may also have a deterrent effect for other forms of criminal homicide. As Caldwell points out, the fact that society so condemns murder that it demands the life of the offender "helps to engender attitudes of dislike, contempt, disgust, and even horror of these acts, and thus contributes to the development of personal forces hostile to crime" (425-6).

\section{CERTAINTY OF EXECUTION}

Three measures of certainty of execution are considered. First, execution rates were computed by dividing the number of executions for homicide during the year by the number of reported criminal homicides during the year. This procedure resulted in an execution rate value for each state that could range from zero to unity. This execution measure is based on the assumption that the general public, including would-be killers, is more affected (deterred) by its impression of current levels of homicide and executions than by the current level of homicides and future executions, and/or previous homicides and the current level of executions.

Second, if the public is sensitive to the typical delay of at least one year between the commission of murder and execution, then it makes sense to take a time lag into account. A second execution rate measure was constructed by dividing the number of executions for murder during the year (year $t$ ) by the number of reported homicides for the previous year (year $t-1$ ).

A third execution rate measure was computed by dividing the average number of executions for a three-year consecutive period ((yr. $t-1$ $+\mathrm{yr} . t+\mathrm{yr} . t+1) / 3$ ) by the number of reported homicides for year $t$. This operationalization has some advantages over the above indexes (Forst). If the public has only a vague notion of the level of executions during any particular year, then it makes more sense to compute execution rates by comparing the level of homicides during year $t$ with the level of executions for that year and neighboring years. Second, due to the small number of executions during 1960, measurement error and sampling variability can be reduced by considering the mean number of executions for a three-year 
period. For each certainty of execution measure, execution rates were converted from proportions into percentages in the analysis presented in Tables 2-9.

\section{CELERITY OF EXECUTION}

In examining the celerity of the death penalty, ideally one would like to consider the time intervals both between the commission of murder and executions, and between sentencing and executions. Unfortunately, published data for either measure are not available. Thanks to the assistance of the National Prisoners Statistics Branch of the Bureau of the Census, however, I was able to secure unpublished data for the median elapsed time in months between the sentence of death and execution of convicted murderers from 1956 to $1960 .{ }^{6}$ As explained by the Bureau, these data have been compiled since 1956, but the Bureau has been unable to locate figures for most states since 1960.7 Figures are not available from the Bureau for the elapsed time between the commission of murder and executions.

Celerity figures for each year and for the five-year period are presented in Table 1 . As can be seen, the median elapsed time for all states combined varies only slightly from year to year. In contrast, figures vary substantially for states each year, and for the five-year period. For a number of states for individual years, and for some states for all five years $(n=9)$, median figures could not be computed since there were no executions for murder these years.

Figures in Table 1 were initially used to compute two measures of celerity: the average median elapsed time between sentence of death and execution between (1) 1956 and 1960, and (2) 1958 and 1960. ${ }^{8}$ Both measures were considered on the assumption that the public's impression of the delay in executions is more a result of sentencing and execution practices over the past few years than during any one year. Analysis revealed a rather substantial association between these two measures $(r=.707)$, and a very similar association between celerity figures lagged by one year (1959) and average figures for 1956 to $1960(r=.900)$, and for 1958 to 1960 $(r=.907) .{ }^{9}$ In addition, the results of the analysis (to be presented later) were virtually identical regardless of which celerity measure was selected. As a result, and to extend degrees of freedom, I choose to use median figures for the period 1956 to $1960(n=31)$ rather than 1958 to $1960(n=25) .{ }^{10}$

\section{CERTAINTY AND SEVERITY OF IMPRISONMENT}

Certainty and severity of imprisonment for homicide are considered as control variables. Using figures published by the Federal Bureaus of Investigation and Prisons, estimates of the certainty of imprisonment for 1960 were computed for each state by dividing the number of convicted mur- 
Table 1. MEDIAN ELAPSED TIME IN MONTHS BETWEEN SENTENCE OF DEATH AND EXECUTION OF CONVICTED MURDERERS BY STATE AND YEAR OF EXECUTION

\begin{tabular}{|c|c|c|c|c|c|c|}
\hline State & 1956 & 1957 & 1958 & 1959 & 1960 & $1956-1960$ sts \\
\hline Alabama & . . & 13.6 & . . & 11.6 & 16.8 & 14.0 \\
\hline Arizona & . & 22.2 & 46.6 & 17.6 & 20.7 & 26.8 \\
\hline Arkansas & . . &. & . . & 11.4 & 18.0 & 14.7 \\
\hline Californiat & 19.4 & 13.8 & 51.7 & 16.2 & 13.1 & 22.8 \\
\hline Colorado & 18.4 & 7.9 & $\cdot \cdot$ & $\cdot \cdot$ & 67.4 & 31.2 \\
\hline Connecticut & $\cdot \cdot$ & . & $\cdot$. & 57.4 & 34.7 & 46.1 \\
\hline Florida & 24.5 & 29.6 & 36.4 & 24.7 & 19.4 & 26.9 \\
\hline fieorgiat* & 11.9 & 10.3 & 14.7 & 9.0 & 2.0 & 9.6 \\
\hline Idaho & . . & 10.4 & $\cdot \cdot$ & $\cdot$. & . . & 10.4 \\
\hline Illinois & $\cdot \cdot$ & . . & 36.9 & $\cdot$. & . . . & 36.9 \\
\hline Indiana & $\cdot \cdot \cdot$ & $\cdot \cdot$ & $\cdot \cdot$ & $\cdot \cdot$ & $\cdot \cdot$ & $\cdot \cdot$ \\
\hline lowa & . . & . . & $\cdot \cdot$ & . . . & . . &.. \\
\hline Kansas & $\cdot \cdot$ & $\cdot \cdot$ & $\cdot \cdot$ & $\cdot \cdot$ & $\cdot \cdot$ & $\cdot \cdot \cdot$ \\
\hline Kentucky & 18.2 & . . & . . & $\cdot \cdot$ & . . . & 18.2 \\
\hline Louisiana & 23.3 & 24.0 & 12.3 & . . & . . & 19.9 \\
\hline Maryland & . . & 11.3 & . . & 12.2 & . . . & 11.8 \\
\hline Massachusetts & . . & - . & $\cdot \cdot$ & $\cdot \cdot$ & . . & $\cdot$. \\
\hline Mississippi & 7.8 & 24.1 & 29.9 & . . & . . & 20.6 \\
\hline Missouri & . . & 19.1 & . . & $\cdot \cdot$ & . . & 19.1 \\
\hline Nebraska & . . & . . & . . & 12.6 & . . & 12.6 \\
\hline Nevada & $\cdot \cdot$ & . . & $\cdot \cdot$ & $\cdot$. & 22.0 & 22.0 \\
\hline New Hampshire & $\cdot \cdot$ & $\cdot \cdot$ & $\cdot \cdot$ & . . . & $\cdot \cdot$ & $\cdot \cdot$ \\
\hline New Jersey & 29.1 & . & . . & . . . & . . . & 29.1 \\
\hline New Mexico & 16.4 & . . & . . &.. & 20.5 & 18.5 \\
\hline New York & 10.8 & 21.4 & 19.2 & 18.2 & 14.4 & 16.8 \\
\hline North Carolina & 23.7 & $\cdot \cdot$ & 11.5 & . . & . . & 17.6 \\
\hline Ohion: & 13.2 & 6.8 & 12.1 & 21.7 & 22.3 & 15.2 \\
\hline Oklahoma & 14.6 & 16.6 & $\cdot$. & . . . & 15.4 & 15.5 \\
\hline Oregon & . . & $\cdot \cdot$ & . . & $\cdot \cdot$ & . . & . . \\
\hline Pennsylvania & 14.1 & $\cdot \cdot$ & $\cdot \cdot$ & 28.1 & . . & 21.1 \\
\hline South Carolina & 11.1 & 21.8 & $\cdot \cdot$ & . . & . . & 16.5 \\
\hline South Dakota & $\cdot \cdot$ & $\cdot$. & $\cdot \cdot$ & . . & . . & $\cdot \cdot$ \\
\hline Tennessee & . . & 10.6 & $\cdot \cdot$ & $\cdot \cdot$ & . . & 10.6 \\
\hline Texas & $3 \cdot 3$ & 6.6 & 8.0 & 2.4 & 2.9 & 4.6 \\
\hline Utah & 78.7 & . & 16.9 & $\cdot \cdot$ & 27.4 & 41.0 \\
\hline Vermont & . . & . . & . . & . . &. & . . \\
\hline Virginia & . . & 2.0 & 2.1 & 5.4 & 15.1 & 6.2 \\
\hline Washington & 28.7 & 28.2 & $\cdot$. & . . . & 1.2 & 19.4 \\
\hline West Virginia & 3.8 & . . & 7.3 & 20.0 & . . & 10.4 \\
\hline Wyaning & $\cdot \cdot$ & . . & $\cdot \cdot$ & $\cdot \cdot$ & . . & $\cdot \cdot$ \\
\hline All states & 14.0 & 13.5 & 15.3 & 13.6 & 15.4 & 14.4 \\
\hline
\end{tabular}

*The median time lapsed is computed on the basis of "date first received in prison't to execution. In California the number of days between sentencing and delivery to prison was small, seldom more than a weekend. For ohio the delay was also quite brief, generally i to 5 days. Accordingly, for these two states these short delays should have relatively little impact on the monthly median figures.

** Georgia officials indicate that in some cases the sentencing date was reported and in some cases the date received at prison was reported in computing median figures. The median time lapse figures for this state are thus understated to some unknown degree.

\#2 The arithmetic mean of the median figures from 1956 to 1960 are reported in this column. 
derers imprisoned during the year by the number of reported murders during the year. Because required imprisonment data are only available for one year (1960) during the period where celerity data are available, analysis is confined to 1960 .

The measure used for severity of imprisonment for homicide is the median length of prison sentence served by convicted murderers released from prison in 1960. These median data were also secured from the Federal Bureau of Prisons, and are also only available for one year (1960) during the 1956 to 1960 period.

For the 40 states shown in Table 1, estimates of certainty of imprisonment could be computed for all but one jurisdiction (New Jersey), and for all but three states (New Jersey, Idaho, Wyoming) for the severity of imprisonment. Certainty and severity estimates could not be computed for New Jersey due to New Jersey officials' failure to report the required data. Severity estimates were not possible for Idaho and Wyoming since there were no murderers released from prison during the year.

\section{SOCIODEMOGRAPHIC CONTROL VARIABLES}

To control for possible spuriousness, a number of sociodemographic factors were considered as control variables: (1) population; (2) population density; (3) proportion urban population; (4) proportion nonwhite population; (5) proportion male population; (6) proportion population 20-40 years of age; (7) median education; (8) median family income; (9) percentage unemployment; and (10) a binary southerness variable, where southern states $=1$ and nonsouthern $=0 .{ }^{11}$

Due to the association among some of these variables (multicollinearity), all of the sociodemographic factors could not be considered in the final model. To eliminate redundant variables, homicide rates were regressed against the four sanction variables and various combinations of sociodemographic variables. This procedure resulted in the selection of four control variables to include in the final model: nonwhite population; urban population; population $20-40$ years of age; and median family income.

To check that an important factor among the remaining six sociodemographic variables had not been mistakenly excluded, each, one at a time, was combined with the four sanction and four selected control variables and included in a series of regressions. This procedure failed to add significantly to the size of the multiple $R^{2}$ value, with the execution and imprisonment coefficients being altered only slightly and insignificantly. ${ }^{12}$ 


\section{METHOD OF ANALYSIS}

The general model examined here is

$\mathrm{HR}=f($ EXRT, EXCEL, CERT, SEV, AGE, INC, NW, URB).

This model represents the hypothesis that homicide rates (HR) are influenced by execution rates (EXRT), the celerity of execution (EXCEL), the certainty of imprisonment (CERT), the length of prison sentence (SEV), and the sociodemographic characteristics of age (AGE), median family income (INC), nonwhite population (NW), and urban population (URB).

Ordinary least-squares regressions were performed to examine the hypotheses of (1) a significant inverse relationship between state homicide rates and the certainty of executions, and the certainty and severity of imprisonment, and (2) a positive relationship between delays in execution and homicide rates. As noted, multiple execution rate measures are considered, and to explore both the immediate and possible delayed deterrent effect of executions and imprisonment, two homicide rate measures are considered: (1) homicide rates per 100,000 population for 1960; and (2) mean homicide rates per 100,000 population for 1960 and $1961 .{ }^{13}$

\section{THE SIMULTANEITY OF THE SANCTION-OFFENSE RATE RELATIONSHIP}

The sanction-offense rate model rests on the assumption that sanctions influence homicide rates. It is plausible, however, that the level of homicides also influences sanction levels for homicide. If this is the case, our model will yield biased results for the sanction variables.

To test this question, homicide rates for year $t-1$ (1959) and the four sociodemographic variables included in our model were regressed against the sanction variables. Like some previous investigators (Black and Orsagh), a one-year lag was assumed in how levels of homicide might influence sanction levels. Results fail to show sanctions to be responsive to homicide rates. Only a very slight trade-off is observed between 1959 homicide rates and 1960 execution rates $(B=.015)$, one-year lagged execution rates $(B=.001)$ and three-year mean execution rates $(B=.001)$. Similarly, the trade-off between homicide rates and certainty $(B=-.001)$ and severity $(B=-.001)$ of imprisonment is also very slight. ${ }^{14}$ These results lead to the conclusion that the findings to be presented here are not seriously biased due to simultaneity.

\section{Findings}

Table 2 reports the analysis when sanctions and homicide rates are examined for 1960 (upper panel), and when mean homicide rates for 1960 and 
Tablo 2. RELATIONSHIP BETWEEN CELERITY OF EXECUTION, EXECUTION RATES, CERTAINTY AND SEVERITY OF IMPRISONMENT, SELECTED SOCIODEMOGRAPHIC VARIABLES, AND HOMICIDE RATES

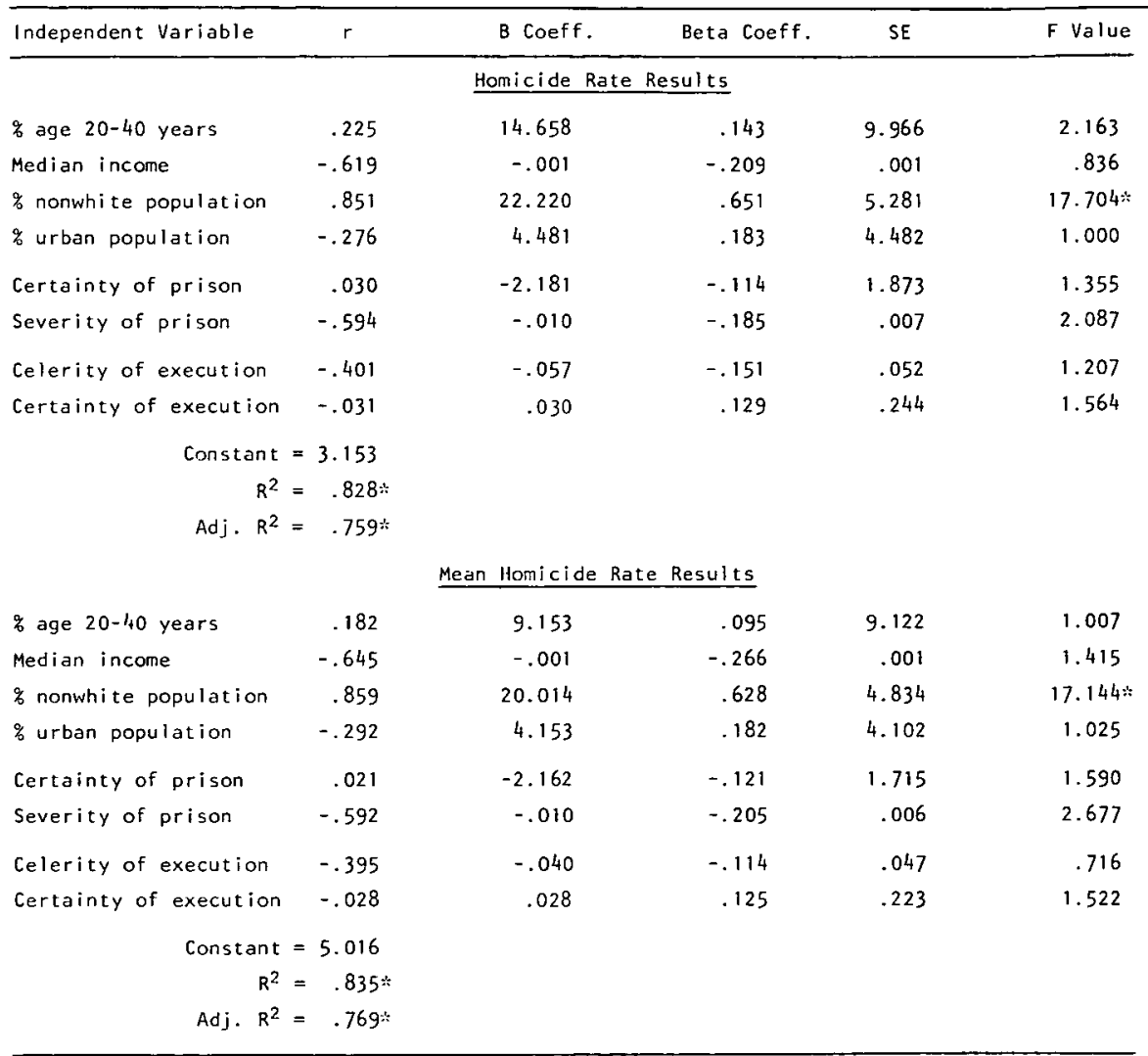

Sources: Homicide rate figures from F.B.I., 1961; celerity of execution figures from Bureau of the Census, Demographic Survey Division, National Prisoners Statistics Branch; certainty and severity of imprisonment figures from Federal Bureau of Prisons, 1960. Execution rates were computed on the basis of homicide and execution figures that came respectively from F.B.I., 1961, and Federal Bureau of Prisons, 1967. Socioeconomic and demographic data from U.S. Department of Commerce, 1964.

$* \mathrm{P}<.001$.

1961 are used as the dependent variable (lower panel). For both measures of homicide, analysis reveals a consistent pattern. When 1960 offense rates are considered, the partial regression $(B)$ coefficients fall in the predicted negative direction for the certainty $(-2.181)$ and severity $(-.010)$ of imprisonment, but not for the certainty of executions (.030). In addition, the celerity coefficient is negative $(-.057)$, whereas the deterrence argument suggests a positive association between the length of the interval between sentencing and execution and homicide rates. None of the sanction coefficients is statistically significant.

When mean homicide rates are examined, the coefficients are nega- 
tive for the certainty $(-2.162)$ and severity $(-.010)$ of imprisonment, and for the celerity of the death penalty $(-.040)$, but positive for execution rates (.028). Table 2 also shows that sizes of the respective coefficients are very comparable for the sanction variables in the yearly and mean homicide rate analysis.

These findings provide no support for the deterrence hypothesis for the certainty and celerity of the death penalty. The nonsignificant findings for the certainty and severity of imprisonment are also inconsistent with the deterrence argument.

Table 3 presents the results when a one-year lagged execution rate

Table 3. RELATIONSHIP BETWEEN CELERITY OF EXECUTION, ONE-YEAR LAGGED EXECUTION RATES, CERTAINTY AND SEVERITY OF IMPRISONMENT, SELECTED SOCIODEMOGRAPHIC VARIABLES, AND HOMICIDE RATES

\begin{tabular}{|c|c|c|c|c|c|}
\hline Independent Variable & $r$ & B Coeff. & Beta Coeff. & SE & F Value \\
\hline \multicolumn{6}{|c|}{ Homicide Rate Results } \\
\hline$\%$ age $20-40$ years & .225 & 14.404 & .140 & 9.901 & 2.116 \\
\hline Median income & -.619 & -.001 & -.202 & .001 & .790 \\
\hline$\%$ nonwhite population & .851 & 22.418 & .657 & 5.265 & $18.129 \%$ \\
\hline Zurban population & -.276 & 4.379 & .179 & 4.458 & .965 \\
\hline Certainty of prison & .030 & -2.329 & -.122 & 1.880 & 1.535 \\
\hline Severity of prison & -.594 & -.010 & -.182 & .007 & 2.057 \\
\hline Celerity of execution & -.401 & -.064 & -.172 & .053 & 1.464 \\
\hline Certainty of execution & -.068 & .259 & .146 & .192 & 1.809 \\
\hline \multicolumn{6}{|c|}{ Constant $=3.332$} \\
\hline \multicolumn{6}{|c|}{$\mathrm{R}^{2}=.830^{*}$} \\
\hline \multicolumn{6}{|c|}{ Adj. $R^{2}=.762 *$} \\
\hline \multicolumn{6}{|c|}{ Mean Homicide Rate Results } \\
\hline$\approx$ age $20-40$ years & .182 & 8.913 & .093 & 9.086 & .963 \\
\hline Median income & -.645 & -.001 & -.260 & .001 & 1.360 \\
\hline$\checkmark$ nonwhite population & .859 & 20.167 & .632 & 4.832 & $17.422 \%$ \\
\hline$\%$ urban population & -.292 & 4.066 & .178 & 4.091 & .988 \\
\hline Certainty of prison & .021 & -2.283 & -.128 & 1.725 & 1.752 \\
\hline Severity of prison & -.592 & -.010 & -.203 & .006 & 2.654 \\
\hline Celerity of execution & -.395 & -.046 & -.131 & .049 & .890 \\
\hline Certainty of execution & -.069 & .227 & .137 & .177 & 1.654 \\
\hline \multicolumn{6}{|c|}{ Constant $=5.182$} \\
\hline \multicolumn{6}{|c|}{$R^{2}=.836 *$} \\
\hline $\operatorname{Adj} \cdot R^{2}$ & $=.771 \%$ & & & & \\
\hline
\end{tabular}

Sources: Homicide rate figures from F.8.1., 1961; celerity of execution figures from Bureau of Census, Demographic Survey Division, National Prisoners Statistics Branch; certainty and severity of imprisonment figures from Federal Bureau of Prisons, 1960. Execution rates were computed on the basis of homicide and execution figures that came respectively from F.B.I., 1961, and Federal Bureau of Prisons, 1967. Socioeconomic and demographic data from U.S. Department of Commerce, 1964.

$\# p<.001$. 
measure is considered. The 1960 homicide rate analysis yields negative coefficients for the certainty $(-2.329)$ and severity $(-.010)$ of imprisonment, and for the celerity of executions $(-.064)$. The coefficients are also negative in the mean homicide rate analysis for the certainty $(-2.283)$ and severity $(-.010)$ of imprisonment, and the celerity of the death penalty $(-.046)$. As before, neither the imprisonment nor the celerity coefficient is statistically significant.

In contrast, lagged execution rates are positively associated with yearly $(B=.259)$ and mean homicide rates $(B=.227)$. Accordingly, we again find no evidence that homicide rates are responsive to the death penalty.

Three-year mean execution rates are introduced into the analysis reported in Table 4. For each measure of homicide, the coefficients are consistently negative for both imprisonment variables and the celerity of the death penalty. In contrast, execution rates and both measures of homicide are positively related, although the coefficients are again not statistically significant.

In sum, these findings provide no support for the deterrence argument for the certainty of the death penalty, with homicide rates being positively related with each measure of execution. Second, both homicide rates are negatively related to the celerity of the death penalty, but the celerity coefficients are very slight and are not significant. Accordingly, no support is found for the argument that delays in execution are positively related with homicide rates. Third, although certainty and severity of imprisonment are negatively associated with both measures of homicide, the findings are not statistically significant.

Finally, while not of primary interest, comparison of the findings for the sanction versus the sociodemographic variables also reveals a rather consistent pattern. The Beta results consistently show nonwhite population to be the best predictor of offense rates, followed by median family income. Next comes severity of imprisonment, which ranks third in importance in four of the six analyses, then followed by urban population, which ranks fourth in four of the six analyses. These factors are followed by the two execution variables, and lastly by age and certainty of imprisonment, which prove to be the poorest predictors of homicide. These results are consistent with the findings of most previous investigations that homicide rates are more responsive to sociodemographic factors (nonwhite, income, urban) than imprisonment (certainty and severity), and are not responsive to executions (certainty, celerity).

\section{NONLINEARITY OF THE SANCTION-OFFENSE RATE RELATIONSHIP}

In the foregoing analysis the form of the relationship between the sanction and offense variables was assumed to be linear. But there is a possibility 
Tablo 4. RELATIONSHIP BETWEEN CELERITY OF EXECUTION, THREE-YEAR MEAN EXECUTION RATES, CERTAINTY AND SEVERITY OF IMPRISONMENT. SELECTED SOCIODEMOGRAPHIC VARIABLES, AND HOMICIDE RATES

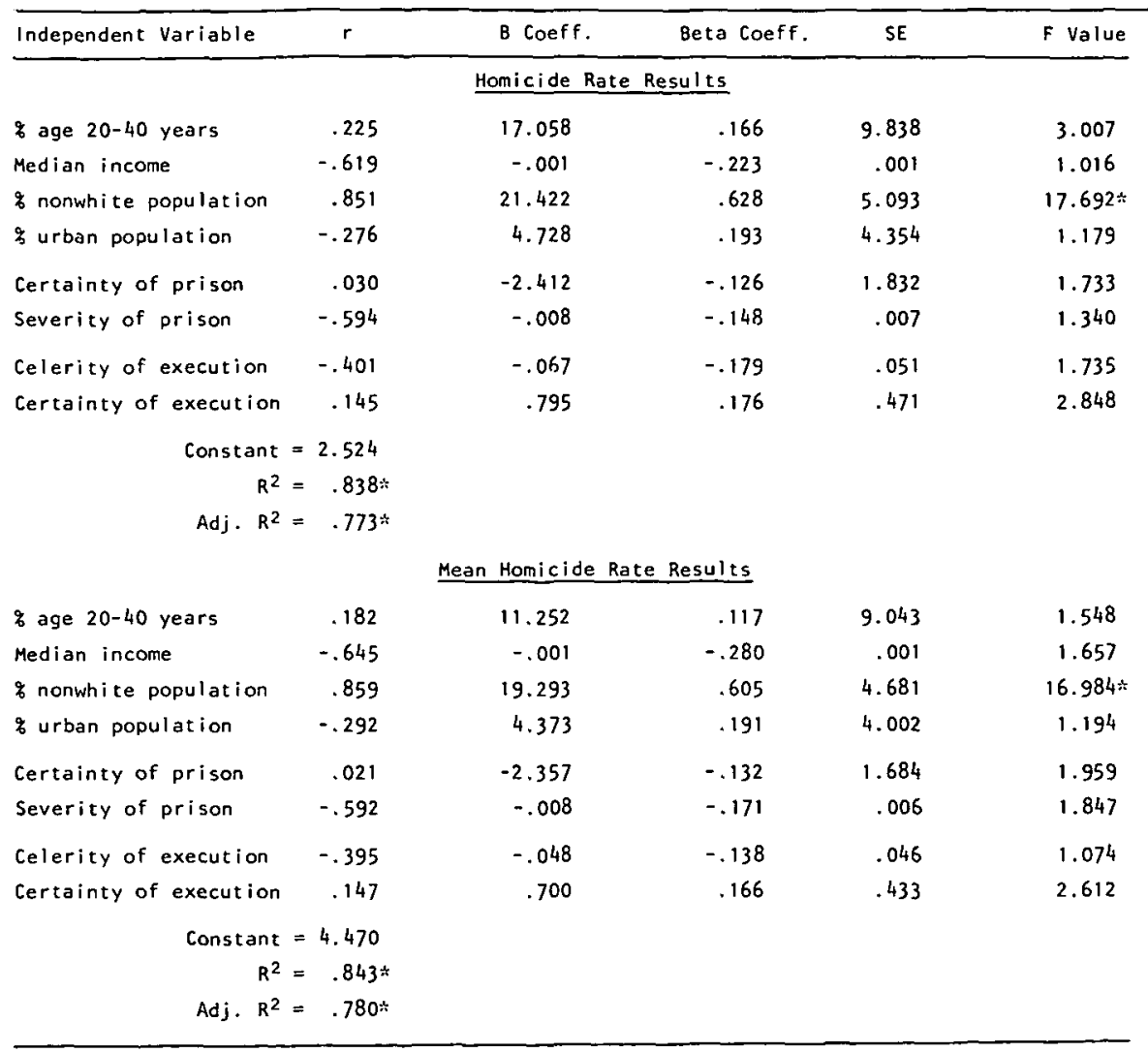

Sources: Homicide rate figures from F.B.I., 1961; celerity of execution figures from Bureau of the Census, Demographic Survey Division, National Prisoners Statistics Branch; certainty and severity of imprisonment figures from Federal Bureau of Prisons, 1960. Execution rates were computed on the basis of homicide and execution figures that came respectively from F.B.I., 1961, and Federal Bureau of Prisons, 1967. Socideconomic and demographic data from U.S. Department of Commerce, 1964.

sp $<.001$.

that the actual form of the relationship is nonlinear. To provide a test of this question, natural log transforms were performed on the homicide rate variables and the above analysis was repeated.

Table 5 reports the analysis when both the sanction variables and the transformed homicide rates are examined for 1960, and when transformed mean homicide rates are used as the dependent variable. This analysis reveals similar findings but there are some points of contrast to Table 2. With the exception of execution rates, each of the sanction variables is negatively related with both homicide measures. Likewise, neither 
Table 5. RELATIONSHIP BETWEEN CELERITY OF EXECUTION, EXECUTION RATES, CERTAINTY AND SEVERITY OF IMPRISONMENT, SELECTED SOCIODEMOGRAPHIC VARIABLES, AND LOG HOMICIDE RATES

\begin{tabular}{|c|c|c|c|c|c|}
\hline Independent Variable & $r$ & B Coeff. & Beta Coeff. & SE & F Value \\
\hline \multicolumn{6}{|c|}{ Homicide Rate Results } \\
\hline$\%$ age $20-40$ years & .173 & 2.824 & .117 & 2.762 & 1.045 \\
\hline Median income & -.425 & -.001 & -.051 & .000 & .036 \\
\hline$\%$ nonwhite population & .728 & 4.823 & .601 & 1.463 & $10.861 \%$ \\
\hline$\%$ urban population & -.091 & 1.881 & .327 & 1.242 & 2.294 \\
\hline Certainty of prison & .031 & -.526 & -.117 & .519 & 1.025 \\
\hline Severity of prison & -.652 & -.003 & -.236 & .002 & 2.448 \\
\hline Celerity of execution & -.500 & -.032 & -.360 & .014 & $4.907 *$ \\
\hline Certainty of execution & -.007 & .010 & .181 & .068 & 2.206 \\
\hline Constant & $=.413$ & & & & \\
\hline$R^{2}$ & $.761 \div * *$ & & & & \\
\hline Adj. $R^{2}$ & $.665 * * *$ & & & & \\
\hline \multicolumn{6}{|c|}{ Mean Homicide Rate Results } \\
\hline$\%$ age $20-40$ years & .140 & 1.486 & .070 & 2.284 & .423 \\
\hline Median income & -.505 & -.001 & -.100 & .000 & .158 \\
\hline$\%$ nonwhite population & .771 & 4.316 & .609 & 1.210 & $12.713 \%$ \\
\hline$\%$ urban population & -.166 & 1.305 & .257 & 1.027 & 1.613 \\
\hline Certainty of prison & -.020 & -.680 & -.171 & .429 & 2.509 \\
\hline Severity of prison & -.649 & -.003 & -.254 & .002 & 3.245 \\
\hline Celerity of execution & -.461 & -.023 & -.302 & .012 & 3.944 \\
\hline Certainty of execution & -.021 & .008 & .173 & .056 & 2.309 \\
\hline \multicolumn{6}{|c|}{ Constant $=1.171$} \\
\hline \multicolumn{6}{|c|}{$\mathrm{R}^{2}=.791 \div * *$} \\
\hline $\operatorname{Adj} \cdot R^{2}$ & $.707 * * *$ & & & & \\
\hline
\end{tabular}

Sources: Homicide rate figures from F.B.1., 1961; celerity of execution figures from Bureau of the Census, Demographic Survey Division, National Prisoners Statistics Branch; certainty and severity of imprisonment figures from Federal Bureau of Prisons, 1960.

Execution rates were computed on the basis of homicide and execution figures that came respectively from F.B.1., 1961, and Federal Bureau of Prisons, 1967. Socioeconomic and demographic data from U.S. Department of Commerce, 1964.

$$
\begin{aligned}
* p & <.05 . \\
* 0 & <.01 . \\
* 0 & <.001 .
\end{aligned}
$$

the certainty and severity of imprisonment nor the certainty of execution is significantly related with either measure of homicide. Importantly, and in contrast to Table 2 , celerity of death penalty is now negatively and significantly related with yearly homicide rates.

Table 6 reports the results of the log analysis when one-year lagged execution rates are considered. Execution rates and both homicide rates are again positively associated, and the certainty and severity of imprisonment, and the celerity of the death penalty, are negatively associated with 
Table 6. RELATIONSHIP BETWEEN CELERITY OF EXECUTION. ONE-YEAR LAGGED EXECUTION RATES, CERTAINTY AND SEVERITY OF IMPRISONMENT. SELECTED SOCIODEMOGRAPHIC VARIABLES, AND LOG HOMICIDE RATES

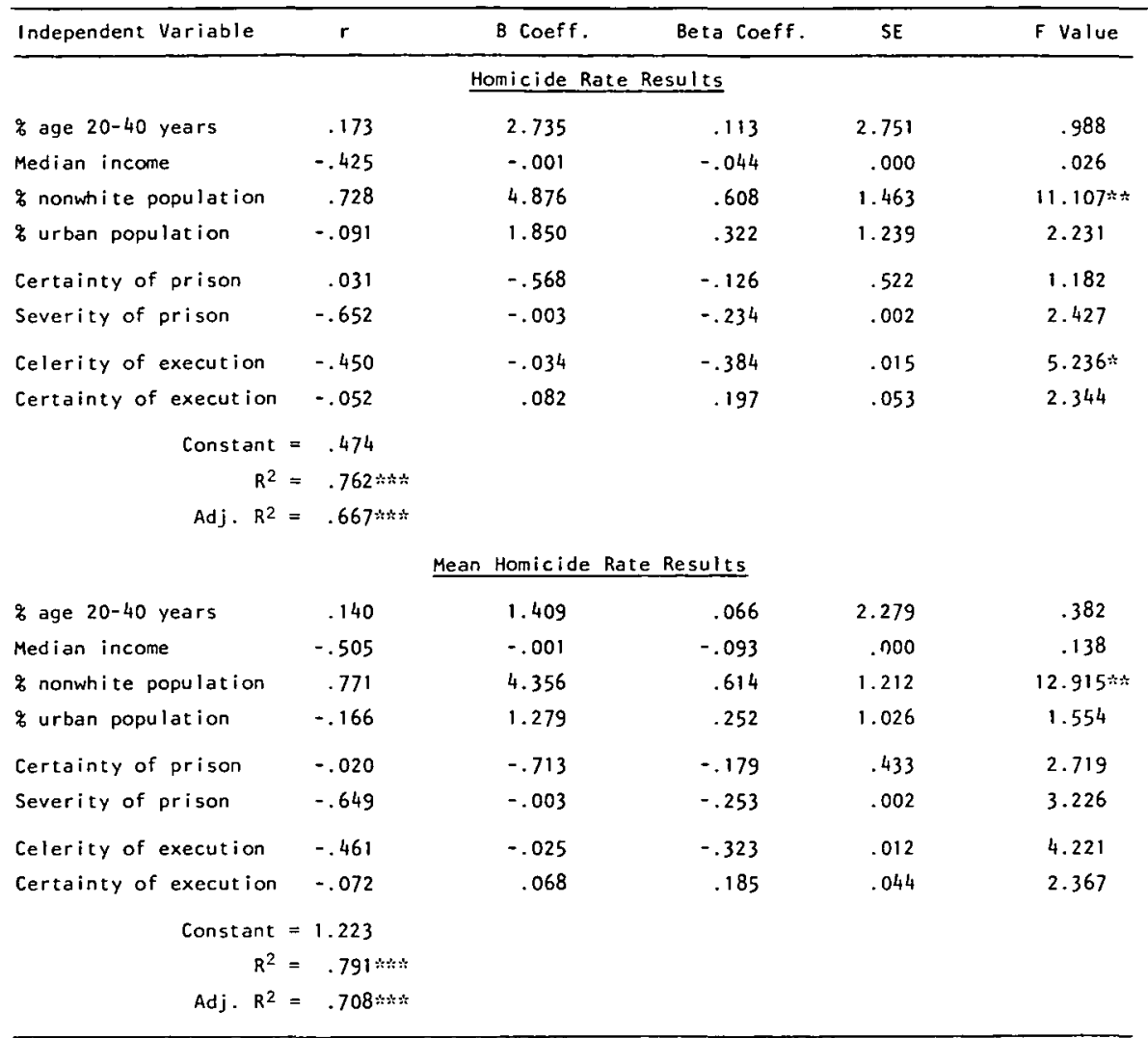

Sources: Homicide rate figures from F.B.I., 1961; celerity of execution figures from Bureau of the Census, Demographic Survey Division, National Prisoners Statistics Branch; certainty and severity of imprisonment figures from Federal Bureau of Prisons, 1960.

Execution rates were computed on the basis of homicide and execution figures that came respectively from F.B.1., 1961, and Federal Bureau of Prisons, 1967. Socioeconomic and demographic data from U.S. Department of Commerce, 1964.

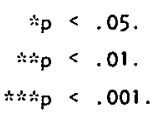

the two dependent variables. With the exception of the celerity of execution1960 homicide rate relationship, the sanction coefficients are not statistically significant. Except for the significant results for the celerity variable in the yearly analysis, these findings closely parallel those in Table 3.

Table 7 reports the results when three-year mean execution rates are considered in the log analysis. As before, we observe a consistent pattern for celerity, but with both celerity coefficients being negative and significant $(P<.05)$. In contrast, the coefficients are negative for the two impris- 
Table 7. RELATIONSHIP BETWEEN CELERITY OF EXECUTION, THREE-YEAR MEAN EXECUTION RATES, CERTAINTY AND SEVERITY OF IMPRISONMENT, SELECTED SOCIODEMOGRAPHIC VARIABLES, AND LOG HOMICIDE RATES

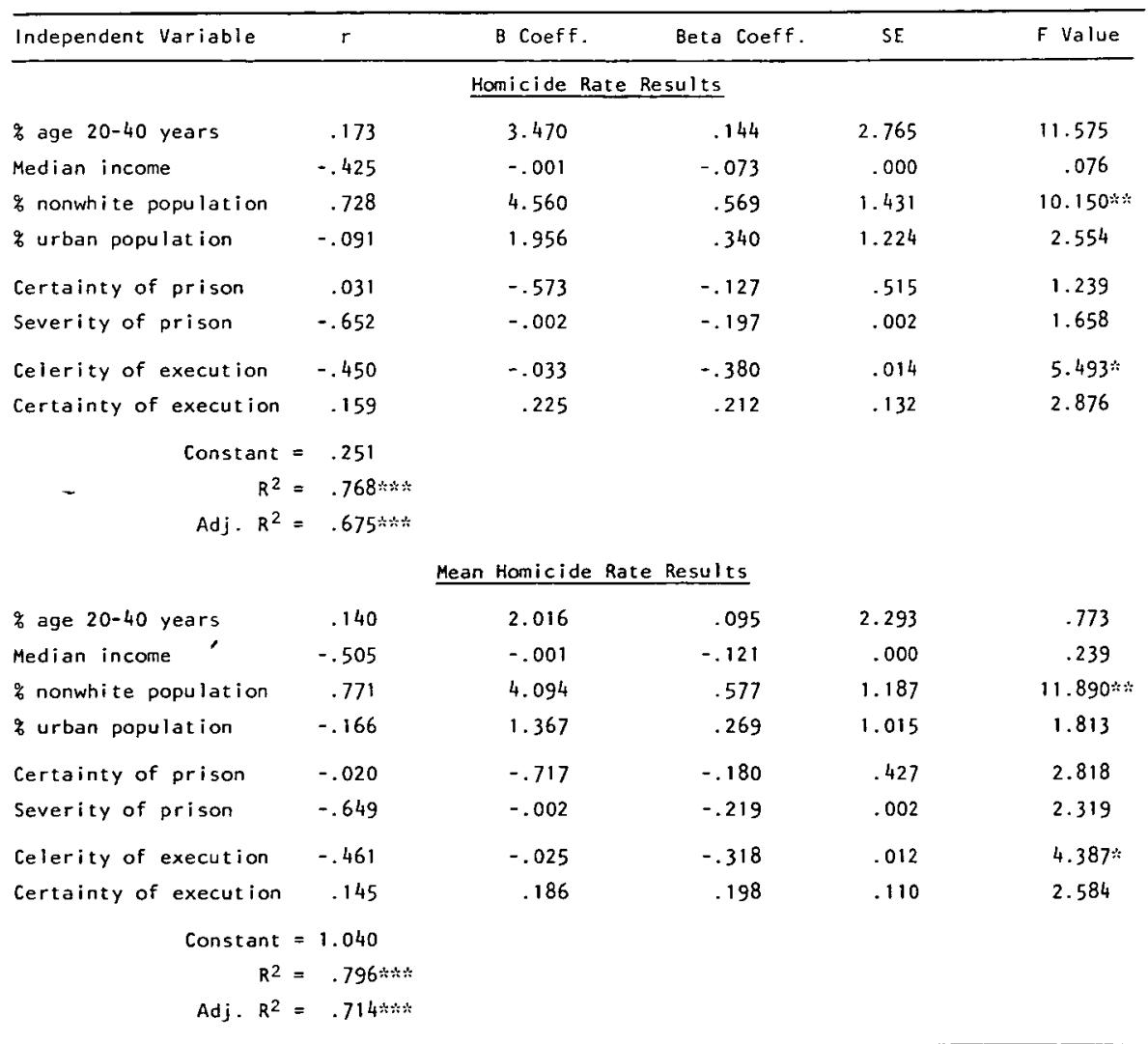

Sources: Homicide rate figures from F.B.I., 1961; celerity of execution figures from Bureau of the Census, Demographic Survey Division. National Prisoners Statistics Branch; certainty and severity of imprisonment figures from Federal Bureau of Prisons, 1960.

Execution rates were computed on the basis of homicide and execution figures that came respectively from F.B.1., 1961, and Federal Bureau of Prisons, 1967. Socioeconomic and demographic data from U.S. Department of Commerce, 1964.

$$
\begin{aligned}
* p & <.05 . \\
*: p & <.01 \\
* * p & <.001 .
\end{aligned}
$$

onment variables, but they are not significant. The same pattern of findings also resulted in the earlier linear analysis (Table 4). In addition, mean execution rates and both homicide rates are again positively related.

In sum, the nonlinear analysis also reveals rather consistent findings, and provides no support for the deterrence argument for either the certainty and severity of imprisonment, or the certainty and celerity of the death penalty. 
The three measures of execution used to this point have all been based on the ratio of reported homicides to executions for homicide. Ehrlich and others have argued, however, that a more appropriate measure would be the ratio of the number of imprisoned murderers to the number of executed murderers. The rationale for this measure is that the public is at least generally aware of the probability of convicted murderers being executed.

To examine this question conditional execution rates were computed for each state by dividing the number of murderers executed during 1960 by the number of murderers imprisoned during the year. Conditional execution values were then substituted in the analysis of homicide rates (as in Table 2) and log homicide rates (as in Table 5). Results of the first analysis appear in Table 8.

A very similar pattern of findings results for the sanction variables as shown in Table 2. For both measures of homicide, the coefficients are negative for certainty and severity of imprisonment, and celerity of execution, but positive for the certainty of the death penalty. None of the sanction coefficients is statistically significant.

Table 9 presents the same analysis, but with log homicide rates. As before (Table 5), the signs, but not levels of significance, for the sanction variables parallel the earlier findings. The coefficients are negative for the certainty and severity of imprisonment and the celerity variable, but only statistically significant for the last variable. As with the earlier findings (Table 8), the certainty of execution coefficients are positive, but statistically significant $(P<.05) .{ }^{15}$

Although not shown here, the same pattern of mixed results for the certainty and celerity of executions shown in Tables 8 and 9 also results when the same linear and nonlinear analysis is performed using conditional execution rates similar to the nonconditional one-year lagged (Tables 3 and 6 ), and the three-year mean (Tables 4 and 7) execution rate measures used earlier. ${ }^{16}$ Because the results so closely parallel the respective findings in Tables 8 and 9 , they can be summarized briefly. Conditional execution rates and log homicide rates (but not homicide rates in their original form) are positively and significantly related. Second, regardless of the homicide and conditional execution measure considered, certainty and severity of imprisonment are not significantly related to offense rates. Third, celerity of execution does not prove to be significantly related to either measure of homicide in their original form, but is positively and significantly related to log homicide rates regardless of which conditional execution measure is considered. Again, the negative sign of the celerity coefficients is opposite from that predicted by the deterrence hypothesis. 
Table 8. RELATIONSHIP BETWEEN CELERITY OF EXECUTION, CONDITIONAL EXECUTION RATES, CERTAINTY AND SEVERITY OF IMPRISONMENT, SELECTED SOCIODEMOGRAPHIC VARIABLES, AND HOMICIDE RATES

\begin{tabular}{|c|c|c|c|c|c|}
\hline Independent Variable & $r$ & B Coeff. & Beta Coeff. & SE & F Value \\
\hline \multicolumn{6}{|c|}{ Homicide Rate Results } \\
\hline$\%$ age $20-40$ years & .225 & 14.967 & .146 & 9.517 & 2.473 \\
\hline Median income & -.619 & -.001 & -.170 & .001 & .602 \\
\hline$\%$ nonwhite population & .851 & 22.678 & .665 & 5.049 & $20.174 \%$ \\
\hline \% urban population & -.276 & 3.530 & .144 & 4.314 & .670 \\
\hline Certainty of prison & .030 & -1.833 & -.096 & 1.765 & 1.078 \\
\hline Severity of prison & -.594 & -.009 & -.180 & .006 & 2.189 \\
\hline Celerity of execution & -.401 & -.059 & -.156 & .048 & 1.507 \\
\hline Certainty of execution & .068 & .190 & .181 & .099 & 3.647 \\
\hline \multicolumn{6}{|c|}{ Constant $=2.727$} \\
\hline \multicolumn{6}{|c|}{$\mathrm{R}^{2}=.843^{*}$} \\
\hline \multicolumn{6}{|c|}{ Adj. $R^{2}=.780 \%$} \\
\hline \multicolumn{6}{|c|}{ Mean Homicide Rate Results } \\
\hline$\%$ age $20-40$ years & .182 & 9.371 & .098 & 8.827 & 1.127 \\
\hline Median income & -.645 & -.001 & -.233 & .001 & 1.145 \\
\hline$\%$ nonwhite population & .859 & 20.347 & .638 & 4.683 & $18.880 *$ \\
\hline \% urban population & -.292 & 3.362 & .147 & 4.001 & .706 \\
\hline Certainty of prison & .021 & -1.847 & -.103 & 1.637 & 1.272 \\
\hline Severity of prison & -.592 & -.010 & -.202 & .006 & 2.812 \\
\hline Celerity of execution & -.395 & -.040 & -.114 & .044 & .817 \\
\hline Certainty of execution & .060 & .160 & .163 & .092 & 2.987 \\
\hline \multicolumn{6}{|c|}{ Constant $=4.680$} \\
\hline \multicolumn{6}{|c|}{$R^{2}=.846 *$} \\
\hline Adj. $R^{2}$ & $.784 \%$ & & & & \\
\hline
\end{tabular}

Sources: Homicide rate figures from F.B.1., 1961; celerity of execution figures from Bureau of the Census, Demographic Survey Division, National Prisoners Statistics Branch; certainty and severity of imprisonment figures from Federal Bureau of Prisons, 1960. Execution rates were computed on the basis of homicide and execution figures that came respectively from F.B.1., 1961, and Federal Bureau of Prisons, 1967. Socioeconomic and demographic data from U.S. Department of Commerce, 1964.

$\therefore p<.001$.

\section{Summary and Conclusions}

In this investigation I have examined a neglected, but theoretically important question; the deterrent effect of the celerity of executions on homicide rates. Both the founders of the classical school of criminology (Beccaria, Bentham) and more recent investigators (Geerken and Gove; Jeffery) have emphasized the importance of the celerity of punishment as a deterrent to crime, but this question has been ignored in death penalty research. 
Table 9. RELATIONSHIP BETWEEN CELERITY OF EXECUTION, CONDITIONAL EXECUTION RATES, CERTAINTY AND SEVERITY OF IMPRISONMENT, SELECTED SOCIODEMOGRAPHIC VARIABLES, AND LOG HOMICIDE RATES

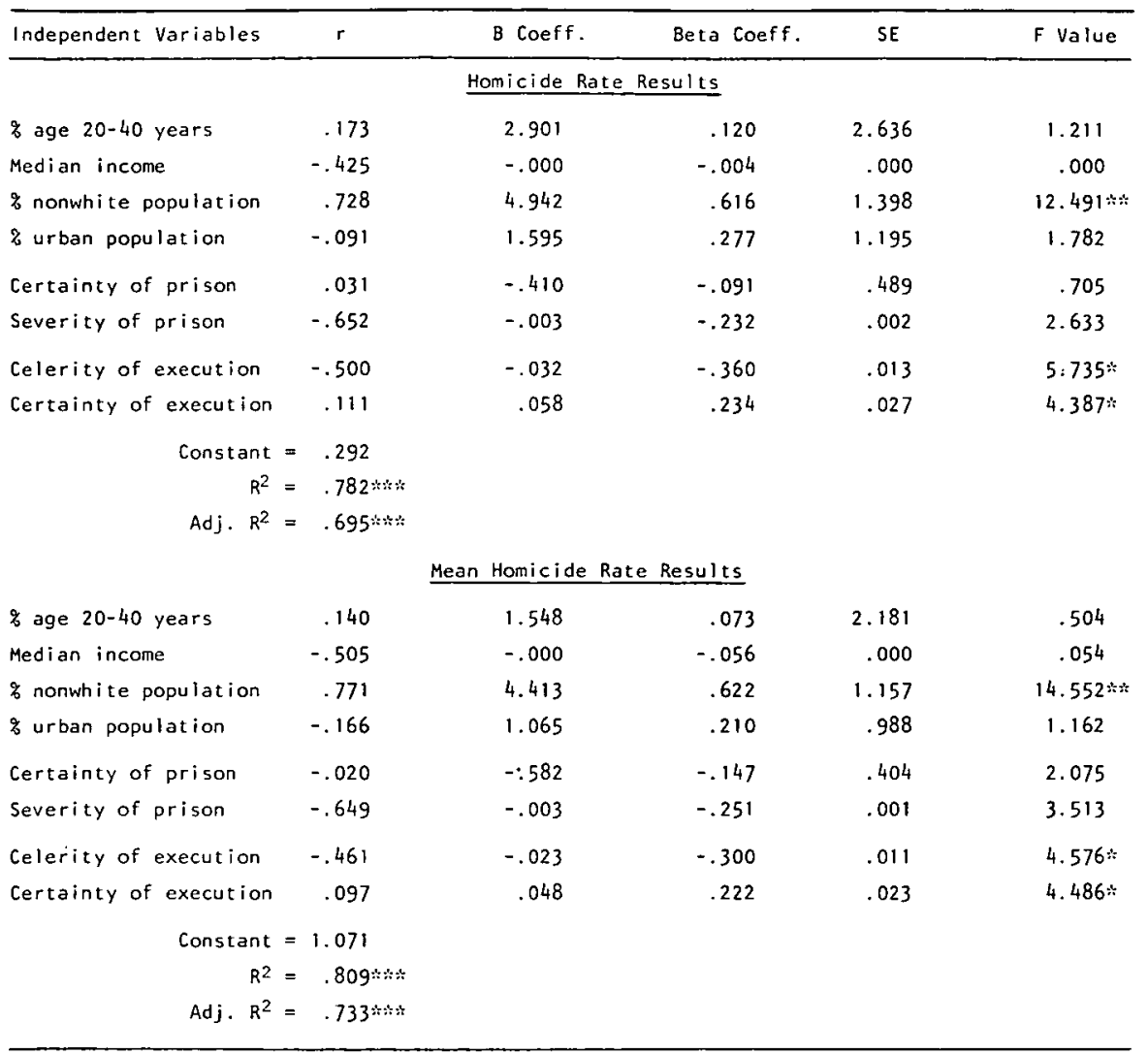

Sources: Homicide rate figures from F.B.1., 1961; celerity of execution figures from Bureau of the Census, Demografhic Survey Division, National Prisoners Statistics Branch; certainty and severity of imprisonment figures from Federal Bureau of Prisons, 1960. Execution rates were computed on the basis of homicide and execution figures that came respectively from F.B.1., 1961, and Federal Bureau of Prisons, 1967. Socioeconomic and demographic data from U.S. Department of Comnerce, 1964.

$$
\begin{aligned}
* p & =.05 \\
x: p & =.01 \\
* x p & <.001 .
\end{aligned}
$$

To explore this question, celerity and the certainty of the death penalty, and certainty and severity of imprisonment, were incorporated in an analysis of state homicide rates for 1960 . To make the analysis comparable to previous investigations, multiple measures of execution and homicide were considered, along with a variety of sociodemographic control variables. Linear and nonlinear forms of the sanction-offense rate relationship were also examined. Briefly, analysis revealed the following. Severity of 
imprisonment was consistently found to be inversely related with homicide rates, but the relationship is very weak $(B<-.005)$, and not statistically significant.

Second, certainty of imprisonment also proved to be inversely related to homicide rates throughout the analysis, but the results are not statistically significant. The lack of support for the certainty of imprisonment is further reflected by the size of the Beta coefficients for certainty and severity of imprisonment. Throughout the analysis, the Betas are larger for the latter variable.

Third, no support is found for the deterrence hypothesis for the certainty of the death penalty. Regardless of the measures of execution and homicide considered, and the assumed functional form of the relationship, certainty of the death penalty consistently proved to be positively related with offense rates. Moreover, for each conditional execution rate measure, the certainty of execution coefficients are statistically significant.

Fourth, at odds with the deterrence hypothesis, the length of the time interval between the sentencing and execution of convicted murderers (celerity of execution) was consistently found to be negatively associated with state homicide rates; states with longer time intervals between sentencing and execution tend to have lower homicide rates.

These findings provide a rather consistent response to the two questions that prompted this study: (1) what is the deterrent effect of the celerity of the death penalty on homicide rates; and (2) have the findings of previous investigations been biased by a failure to consider the celerity of the death penalty? To both of these questions the answer is negative. No support is found for the deterrence argument for celerity of the death penalty, nor is there any evidence that the negative findings reported by most investigators for the certainty of execution are due to their failure to consider celerity.

Before ending this discussion, some possible explanations for the negative findings for the two death penalty variables must be examined. First, although this and previous studies have typically failed to show a significant inverse relationship between the certainty of the death penalty and homicide rates, it might be argued that these negative findings are a result of the low level of executions for murder for the time periods considered (Jeffery).

Although proponents of deterrence are not specific about how certain sanctions must be in order to be effective deterrents to crime, Black and Orsagh conclude that the low level of executions for murder in this country may be responsible for theirs, and others', negative findings for the certainty of executions. For example, for 1960 they estimate that less than 2 percent of convicted first-degree murderers were put to death.

Although I take issue with Black and Orsagh's 2 percent estimate because they base it on the ratio of executions for murder to total criminal 
homicides (not first-degree murders), the fact remains that a number of capital murderers are not executed. If we assume, as Wolfgang and Ferracuti, Sutherland and Cressey and others have, that not more than 5 to 10 percent of criminal homicides are first-degree murders, then the 2 percent figure substantially underestimates execution rates. If execution rates are estimated on the assumption that 90 to 95 percent of criminal homicides are not capital offenses (first-degree murders), then a more realistic estimate of the certainty of the death penalty for murder in 1960 ranges from 20 percent (if we assume that 1.0 in 10 criminal homicides are first-degree murders) to 40 percent (if we assume that 0.5 in 10 criminal homicides are first-degree murders). ${ }^{17}$

These are only rough estimates of execution rates for first-degree murder, but they do illustrate that the certainty of the death penalty for capital homicide was much higher in 1960 than some have assumed. ${ }^{18}$ I must agree with Black and Orsagh, however, that this analysis cannot address the deterrent effectiveness of the death penalty if execution rates were raised to substantially higher levels.

The second concern about my findings is the adequacy of the celerity measure used here. As discussed, I have only been able to use the time interval between the sentencing and execution of convicted murderers. Despite the negative findings for celerity, it might be argued that these results are due to a failure to consider the more appropriate time period between the offense behavior and execution.

Unfortunately, I can only speculate about the merit of this objection, for there are not nationwide data for 1960 (or any other year) on the time interval between the commission of murder and the execution of murderers. If the length of time between the commission of murder and sentencing of capital offenders was relatively uniform (a constant) from state to state in 1960, then our measure of celerity would not yield biased results; the average time period between murder and execution, and sentencing and execution, would be highly correlated. If, however, the interval varied substantially from state to state in 1960 between murders and sentencing of convicted murderers, this analysis would result in somewhat biased findings. (I say "somewhat" because the delay in execution after sentencing is one important contributor to the interval between the commission of murder and execution.)

In short, it is simply not possible to know to what extent (if any) the findings for the celerity of the death penalty are biased due to this difficulty. What is clear, however, is that no support is found for the deterrence hypothesis when one important source of delay in executions is considered.

In conclusion, the findings of this study fall well within the pattern of results of the vast majority of previous investigations. No support whatsoever is found for the argument that the certainty, or celerity, of the death penalty provides an effective deterrent to murder. Although some possible 
limitations of this investigation have been identified, the consistency of the findings with earlier studies cannot be ignored. Nor can it be ignored that not a single reputable study has yet to demonstrate the death penalty to be a more effective deterrent to murder than alternative legal sanctions (Baldus and Cole; Black and Orsagh; Bowers and Pierce; Passell; Passell and Taylor; Peck; Zeisel). For these reasons, and because of the seriousness of the issue, I feel obliged to agree with most previous investigators. The evidence clearly suggests that the death penalty in our criminal justice system, at least for murder, will have to be justified on grounds other than its deterrence effectiveness.

\section{Notes}

1. It is of interest to note that in the Furman decision of 1972 Chief Justice Burger of the United States Supreme Court complained about the lack of clear-cut empirical evidence of a recent vintage on the deterrent effect of the death penalty for murder. Before vacatingFowler $\mathrm{v}$. North Carolina (1976), the Supreme Court received briefs and heard oral arguments in five other death penalty cases in which the findings of a number of post-Furman deterrence investigations were of major concern: Roberts v. Louisiana (1976); Proffitt v. Florida (1976); Woodson v. North Carolina (1976); Jurek v. Texas (1976); Gregg v. Georgia (1976). Although the High Court did not provide any empirical evidence in support of its belief, it did conclude that for many murders "the death penalty undoubtedly is a significant deterrent" (Gregg v. Georgia, 1976, 185-6).

2. Black and Orsagh make the same argument for the possible bias of their results due to their (1) possibly excluding some important nonsanction variable(s) from their model, (2) ignoring the possible deterrent effect of informal sanctions, and (3) use of a log-linear functional form in the analysis.

3. Both Gibbs $(a, b)$ and Andenaes take issue with persons like Jeffrey and Geerken and Gove who base their claims of the deterrent effectiveness of the celerity of legal sanctions upon the findings of psychological laboratory research. As Andenaes argues, analogies drawn from such experimental research to general deterrence are seriously flawed due to the important "differences between the life situation and the experimental setting" (188). To illustrate, whereas laboratory research has been almost exclusively concerned with the effects of actual punishment on experimental subjects, the important question for general deterrence is the effect of the threat of punishment on would-be offenders. In addition, Gibbs (a, 131) further questions the contribution of laboratory research to a better understanding of "specific deterrence" due to the dissimilarity between the laboratory experiment (the setting, subjects and sanctions) and factors of importance to the theory of specific deterrence.

4. Although first-degree murder typically includes the elements of premeditation and malice aforethought, the homicide offense category used by the F.B.I. is much more inclusive; it includes all willful felonious homicides as distinguished from deaths caused by negligence. 5. To illustrate, the bivariate correlations between state execution rates for the five-year periods leading up to 1967 and 1968 and (1) first-degree murder rates for these years (1967, $r=-.137 ; 1968, r=-.194)$, and (2) F.B.I homicide rates for these years (1967, $r=-.166$; $1968, r=-.194)$ are very comparable (Bailey, $a, b)$.

6. Celerity data were supplied to the Federal Bureau of Prisons (which had the responsibility for collecting these data between 1956 and 1971) by state departments of corrections on an individual case basis. Median figures were then computed by the Bureau for each state for each year (see Table 1). The National Prisoners Statistics Branch of the Bureau of the Census has assured me that these data have been checked, and double checked, to guarantee their accuracy.

I would like to express my appreciation to Matthew G. Yeager, Chief Criminologist of the House Subcommittee on Crime, and to the House Subcommittee for their kind assistance in doing much of the leg-work that made it possible to secure celerity of execution data from the Bureau of the Census. 
7. I have, however, been promised additional celerity figures for the years after 1960 when these data are located.

8. Unfortunately, state data for individual cases for the elapsed time between sentencing and execution are not available from the Bureau of the Census. Accordingly, it was not possible to compute median celerity figures for the states on an individual case basis for the periods 1956 to 1960 and 1958 to 1960 . Rather, celerity figures for states had to be computed for these time periods by averaging yearly data for the respective periods.

9. For neighboring years during the period 1956 to 1960 , correlations between yearly celerity figures are: 1956 and $1957(r=.518) ; 1957$ and $1958(r=.558) ; 1958$ and $1959(r=.449) ; 1959$ and $1960(r=.837)$. Especially noting the more substantial correlation for the 1959 to 1960 period, the relatively consistent size of the year-to-year coefficients would suggest that the elapsed time between sentencing and execution is more than simply a "random" variable.

10. Although the concern here is with the deterrent effect of the celerity of executions, and not correlates of celerity, it is of interest to note how this factor relates to the other variables considered in the analysis. The correlations between celerity estimates for the 1956 to 1960 period and the sociodemographic variables are: urban population $(r=.056)$; nonwhite population $(r=-.224)$; population 20 to 40 years of age $(r=-.030)$; median family income $(r=.503)$. The correlations for the imprisonment and execution rate variables considered in Tables 2-9 are: certainty of imprisonment $(r=-.013)$; severity of imprisonment $(r=.504)$; execution rates $(r=.370)$; one-year lagged execution rates $(r=.458)$; three-year mean execution rates $(r=.305)$; conditional execution rates $(r=.099)$.

Although the bivariate correlations are statistically significant between celerity and some of these variables (family income, $P<.01$; severity of imprisonment, $P<.02$; execution rates, $P<.05$; one-year lagged execution rates, $P<.01$ ), celerity of execution does not prove to be so collinear with these factors that they cannot be considered in the same equation. To illustrate, for the variables of primary interest here, the standard errors shown in Table 2 for the execution rate and celerity of executions variables are quite low. A similar pattern holds throughout the remainder of the analysis (Tables 3-9).

11. No explicit theory of homicide is reflected in the sociodemographic variables chosen for the analysis. (No adequate theory of variation in homicide rates can be found in the criminology literature.) Rather, sociodemographic variables were chosen on the basis of their use in previous deterrence and death penalty research, which will thus better allow us to compare our findings with those of previous studies.

12. Regardless of the additional sociodemographic variables considered, nonwhite population continues to be significantly $(P<.001)$ related with homicide rates, and the best predictor of the dependent variable.

13. Forst and Black and Orsagh make an argument for the use of weighted regressions in their analyses because the variance in homicide rates is often larger in more populated states (heteroscedasticity), which results in biased standard errors and tests of significance. In neither investigation, however, is heteroscedasticity found to be a problem, with Black and Orsagh, for example, only finding a very slight inverse relationship $(r=-.03)$ between state population and the size of the residuals.

In this investigation as well, heteroscedasticity does not provide a difficulty. When population size and the residuals resulting from various combinations of execution and homicide rates were correlated, the coefficients also proved to be low-negative, and not significantly different from zero.

14. Due to the time period considered with the celerity of execution variable (1956-60), this factor was not included in our analysis of the effect of homicide rates for the previous year (1959) on sanction levels for the next year (1960).

15. It is of interest to note that for the first time in the analysis, Table 9 shows both execution variables to be statistically significant, but the signs of the coefficients are in the opposite direction than the deterrence doctrine would predict. This unexpected result would not appear to be a function-a statistical artifact-of the relationship between celerity and conditional execution rates $(r=.309, P>.05)$. The lack of collinearity between these two variables is also indicated by their low standard errors.

16. One-year lagged conditional execution rates were computed by dividing (1) the number of executions for murder in 1961 by (2) the number of convicted murderers imprisoned in 1960. Three-year mean conditional execution rates were computed by dividing (1) the average 
yearly number of executions for the period $1959-1961$ by (2) the number of convicted murderers imprisoned in 1960.

17. To illustrate how these percentage figures were derived, assume that in $\mathbf{1 9 6 0}$ there was a ratio of (1) two executions for murder, per (2) 100 criminal homicides. Comparison of these figures $(2 / 100)$ would yield the 2 percent execution rate suggested by Black and Orsagh. If, however, only 10 percent of criminal homicides are first-degree murders $(100 \times 10 \%=10)$, then the execution rate would be $2 / 10$, or 20 percent. Similarly, if only 5 percent of criminal homicides are first-degree murders $(100 \times 5 \%=5)$, then the execution rate would be $2 / 5$, or 40 percent.

18. It was suggested by an anonymous reviewer of this article that estimates of state firstdegree murder rates like those discussed here might be substituted in the analysis so that the results could be compared with our findings which are based upon F.B.I. figures for murder and nonnegligent manslaughter. I have given considerable thought to this suggestion, but have decided against such an analysis on two grounds. First, since it is possible that the ratio of first-degree murders to total criminal homicides is not a constant from state to state, it would be misleading to adjust all state homicide rates by either the 5 or 10 percent figure suggested by Wolfgang and Ferracuti. Second, even if first-degree murder rates were adjusted by 5 or 10 percent (a constant), the results of this study would be essentially unchanged. It is true that the size of the unstandardized coefficients for the sanction and other variables would differ in such an analysis, but importantly: (1) the signs of the regression coefficients would not change, (2) the relative size of the standardized (Beta) coefficients would remain the same, and (3) the level of significance ( $F$-values) associated with each variable would not be altered.

\section{References}

Andenaes, Johannes. 1974. Punishment and Deterrence. Ann Arbor: University of Michigan Press.

Bailey, W. C. a:1974. "Murder and the Death Penalty." Journal of Criminal Law and Criminology 65(December):416-23.

b:1975. "Murder and Capital Punishment: Some Further Evidence." American Journal of Orthopsychiatry 45(July):669-88.

c:1976. "Deterrence Data Reanalyzed." American Journal of Orthopsychiatry 46(July): 568-70.

d:1977. "Imprisonment v. the Death Penalty as a Deterrent to Murder." Law and Human Behavior 1:239-60.

Baldus, D. C., and J. W. Cole. 1975. "A Comparison of the Work of Thorsten Sellin and Isaac Ehrlich on the Deterrent Effect of Capital Punishment." The Yale Law Journal 85(December):170-86.

Beccaria, Cesare B. 1809. Essays on Crimes and Punishment. New York: Gould.

Bedau, Hugo A. 1967. The Death Penalty in America. Rev. ed. New York: DoubledayAnchor Books.

Bentham, Jeremy. 1843. Principles of Penal Law. Edinburgh.

Black, T., and T. Orsagh. 1978. "New Evidence on the Efficiency of Sanctions as a Deterrent to Homicide." Social Science Quarterly 58(March):616-31.

Bowers, W. J., and G. L. Pierce. 1975. "The Illusion of Deterrence in Isaac Ehrlich's Research on Capital Punishment." The Yale Law Journal 85(December):187-208.

Bye, Raymond T. 1919. Capital Punishment in the United States. Philadelphia: Committee on Philanthropic Labor of Philadelphia Yearly Meeting of Friends.

Caldwell, Robert G. 1965. Criminology. New York: Ronald Press.

Ehrlich, I. 1975. "The Deterrent Effect of Capital Punishment: A Question of Life or Death." American Economic Review 65(June):397-417.

Federal Bureau of Investigation. 1961. Crime in the United States: Uniform Crime Reports-1960. Washington: Government Printing Office.

Federal Bureau of Prisons. a:no date. National Prisoner Statistics, 1960. Washington: Government Printing Office. 
b:1967. National Prisoner Statistics: Executions 1930-1966. Washington: Government Printing Office.

Forst, B. E. 1977. “The Deterrent Effect of Capital Punishment: A Cross-State Analysis of the 1960s." Minnesota Law Review 61(May):743-67.

Fowler v. North Carolina. 1976. 428 U.S. 904.

Furman v. Georgia. 1972. 408 U.S. 238.

Geerken, M. R., and W. R. Gove. 1975. "Deterrence: Some Theoretical Considerations." Law and Society Review 9(Spring):497-513.

Gibbs, Jack P. a:1975. Crime, Punishment, and Deterrence. New York: Elsevier.

b:1977. "A Critique of the Scientific Literature on Capital Punishment and Deterrence." Journal of Behavioral Economics 6(Summer/Winter):279-309.

Gregg v. Georgia. 1976. 96 S. Ct. 2909.

Jeffery, C. R. 1965. "Criminal Behavior and Learning Theory." Journal of Criminal Law, Criminology and Police Science 56(September):294-300.

Jurek v. Texas. 1976. 96 S. Ct. 2950.

Kirkpatrick, Clifford. 1925. Capital Punishment. Philadelphia: Committee on Philanthropic Labor of Philadelphia Yearly Meeting of Friends.

Passell, P. 1975. "The Deterrent Effect of the Death Penalty: A Statistical Test." Stanford Law Review 28(November):61-80.

Passell, P., and J. B. Taylor. 1975. "The Deterrent Effect of Capital Punishment: Another View." Discussion Paper 74-7509. Columbia University.

Peck, J. K. 1976. "The Deterrent Effect of Capital Punishment: Ehrlich and His Critics." The Yale Law Journal 85(January):359-69.

Proffitt v. Florida. 1976. 428 U.S. 242.

Roberts v. Louisiana. 1976. 428 U.S. 325.

Schuessler, K. A. 1952. "The Deterrent Influence of the Death Penalty." Annals of the American Academy of Political and Social Science 284(November):54-63.

Sellin, Thorsten. a:1959. The Death Penalty. Philadelphia: American Law Institute. b:1967. Capital Punishment. New York: Harper \& Row.

Sutherland, E. H. 1925. "Murder and the Death Penalty." Journal of the American Institute of Criminal Law and Criminology 15(February):522-529.

Sutherland, Edwin H., and Donald R. Cressey. 1966. Principles of Criminology. 6th ed. Philadelphia: Lippincott.

U.S. Department of Commerce, Bureau of the Census. 1964. Census of Population: 1960. Characteristics of the Population (Vol. 1). United States Summary Part 1. Washington: Government Printing Office.

U.S. Department of Health, Education, and Welfare. 1967. Homicide in the United States: 1950-1964 Washington: Government Printing Office.

U.S. Department of Justice. 1974. Brief for the United States as amicus curiae. Fowler v. North Carolina (428 U.S. 904, 1976).

Vold, G. B. 1932. "Can the Death Penalty Prevent Crimes?" Prison Journal 12(October):3-8.

Woodson v. North Carolina. 1976. 428 U.S. 280.

Wolfgang, Marvin E., and Franco Ferracuti. 1976. The Subculture of Violence. London: Tavistock.

Yunker, J. A. 1976. "Is the Death Penalty a Deterrent to Homicide? Some Time Series Evidence." Journal of Behavioral Economics 1(Summer):45-81.

Zeisel, H. 1976. "The Deterrent Effect of the Death Penalty: Facts v. Faiths." In Philip B. Kurland (ed.), The Supreme Court Review. Chicago: University of Chicago Press. 